\title{
Restor(y)ing the Ground: Digital Environmental Media Studies
}

\author{
AMANDA STARLING GOULD, Duke University
}

\begin{abstract}
This article presents a digital environmental media studies (DEMS) framework that shifts the primary focus of digital media study from one grounded in computation to one fully rooted in the earth. DEMS proposes a relational, metabolic ontology wherein popular media theory terms like atmospheric media, elemental media, cyborg, and digital labor are put to new use to call attention to the evolving, inseparable and transformative, material relations between the human, the earth, and the digital network. Motivated by the absence of environmental thinking from both digital theory and popular digital rhetoric, this article counters by making visible the overlooked intersections of media materiality, social reflexivity, and the environment.
\end{abstract}

\section{KEYWORDS}

Environmental Humanities, Digital Materiality, Digital Media, Digital Environmental Media Studies, \#ActOnClimate

\section{Introduction}
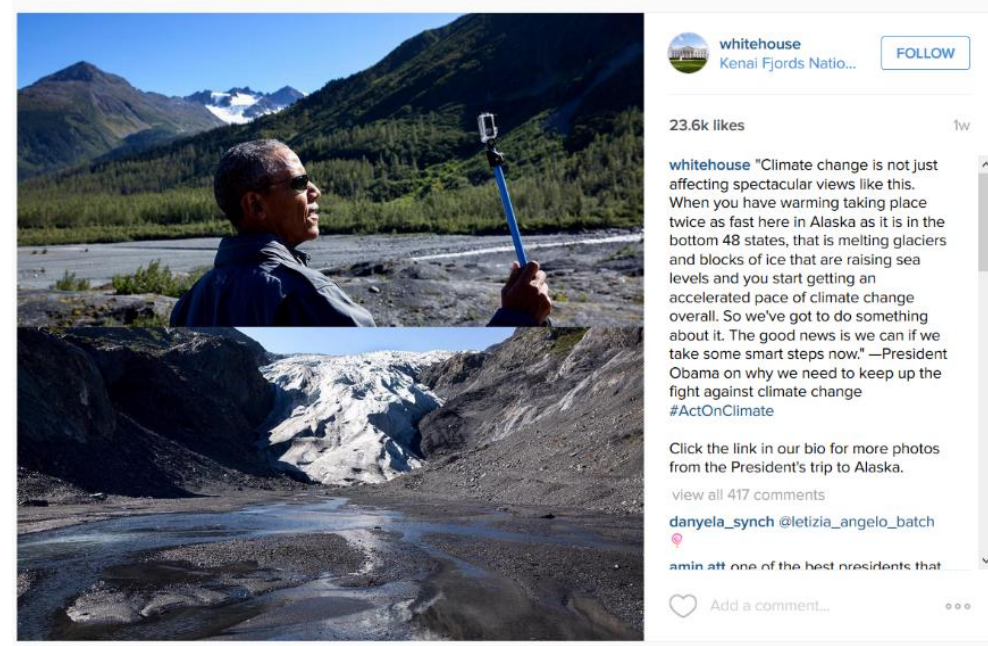

Figure 1: Screenshot from September 5, 2015 White House Instagram post, accessed September 10, 2015. 
On September 5, 2015, U.S. President Obama took a photograph of himself while standing in front of a melting Alaskan glacier. In a deliberate attempt to use social media to call attention to climate change, he posted his 'selfie' on the White House Instagram account with the hashtag \#ActOnClimate. Though the post generated a robust exchange of comments, an almost radical incongruity was overlooked: the very devices and networked connections required to use the mobile-only Instagram platform are among the most noxious of modern contributors to climate change. Digital technology has been sold as the 'green' alternative to material-intensive analog machines, but it most certainly is not: the digital sphere now has a carbon footprint that rivals, and may soon overtake, the aviation industry; our wirelessness requires heavily wired infrastructure; and even our Google searches and spam emails have a carbon footprint. But these are not the stories we tell when we talk about digital media in theory and in popular rhetoric.

In Greening the Media, Richard Maxwell and Toby Miller rightly note that "a deep ecological materiality has eluded the humanistic knowledge of media technology" $(2012,11)$. They point out that the majority of contemporary media studies thinking falls into one of two camps, either humanistic or mechanistic: the humanist focuses primarily on affective results of technologies, while the mechanistic theorist looks at digital media's codes and algorithms. Neither tend properly to the environmental effects of our digital technologies, and, I argue, by situating the digital as an affective (humanist) or algorithmic (machinic) artifact, both actually perform dematerializing abstractions that perpetuate the neglect of concrete environmental thinking in the field. As this article will show, our digital network of connected things and connective infrastructure-what environmental engineer Peter Haff terms the technosphere-is now profoundly entangled with Anthropocenic environmental concerns, and media studies has a role to play in creating new narratives to capture these emerging relations.

This article responds to Maxwell and Miller's call for a deep ecological materiality by introducing a metabolic relational ontology that orients the digital network and digital media as constitutive parts of today's bio- and geo-material metabolisms. A metabolic media framework, which I describe more fully in my project Digital Metabolisms, considers the beginnings (e.g. minerals and metals) and the ends (e.g. wastes, toxins, and pollutants) of digital media as critical sites for contemporary study that link the human, the environment, and digital technology into a dynamic metabolic system. This article and Digital Metabolisms writ large seek to narrate these links, using what I call a digital environmental media studies (DEMS) framework, as a way to begin repairing our technology-related Anthropocene damages. DEMS merges material digital media studies with environmental humanities to shift the digital media focus from one grounded in computation to one fully rooted in the earth. In so doing, it makes inroads in the project to restore, and re-story, digital materiality so as to bring attention to the consequential digital physicalities that are most often deliberately, and dangerously, ignored. 
In DEMS, standard media theory terms are put to new use in order to reconstruct the rhetorically-ruptured relationships between the earth, the human, and technology: ubiquitous computing presumes a corresponding ubiquity of physical, resource-needing, energy-using compounds; digital memory refers not to zip drives but to bioaccumulation and geophysical marks; the figure of the cyborg is re-figured; and our notions of contemporary media become grounded in minerals, manual labor, and e-waste. If our terms become screens through which we see the world, the immaterial implications of many of our prominent media terms (e.g. the Cloud, wirelessness, ubiquitous computing, cognitive labor) may actually create damaging worldviews that deny the digital's relation to the environment and, in so doing, excuse producers and users from any active material responsibilities. Deeply embedded in our current digital stories is a willful material ignorance and an ethical moral pass; and this matters. It matters, Donna Haraway says, "which stories tell stories, which concepts think concepts, mathematically, visually, and narratively it matters which figures figure figures, which systems systematize systems" (2015, 160). DEMS sees new terms and narratives as potential sites for more environmentally-enlightened intervention and engagement, and it asks how an expanded understanding of digital materialities and metabolic relations might lead to a more environmentally-aware media studies, and ultimately to digital narratives that inspire more sustainable behaviors.

A digital environmental media studies, as I here define it, is research that, when placed alongside work by Jenna Burrell, Jussi Parikka, Jennifer Gabrys, Nicole Starosielski, and Sean Cubitt, helps re-embody the digital as literally, and not just figuratively, human and environmental. A digital environmental media studies speaks to the challenge, put forth by Diana Coole and Samantha Frost in their introduction to New Materialisms, for us to "reorient ourselves profoundly in relation to the world, to one another, and to ourselves" in response to recent developments such as climate change, technogenetic engineering, and the "saturation of our intimate and physical lives by digital, wireless, and virtual technologies" (2010, 6). This reorientation is necessary, they say, because a commitment to today's more radical forms of materiality - those that follow our unprecedented $21^{\text {st }}$ century forms of production, reproduction, and consumption - is required to properly account for the ways we live and coexist with nonliving things. Indeed DEMS is informed by the premise that, in our present Anthropocenic age defined by humans acting as a geophysical force, human bodies, cultural technologies, and the earth are intersecting material practices.

If media studies is, as Mark BN Hansen and WJT Mitchell define it in Critical Terms for Media Studies, "a mode of understanding, a perspective from which to engage our world" (Hansen and Mitchell, 2010, xxii), then changing our narratives can help generate new knowledge and methodological structures that reconnect our weightless, wireless digital devices to their physicality and their interpermeable relations. DEMS's relational, metabolic ontology helps us re-story and re-world through its focus on the inherent interconnections between the digital, the 
environmental, and the human. To steal a line from Raymond Williams: we need different stories because we need different relations $(1980,85)$.

In this article, the DEMS metabolic ontology is applied to several common digital media termselemental media, atmospheric media, cyborg bodies, and digital labor - to 'ground' them in their environmental material contexts. In more ways than one, media theory already gives us the terminology we need to begin thinking more environmentally, and this article demonstrates how we might exploit our inclination to metaphorically use environmental terms (e.g. 'environmental media' in theoretical terms refers to the invisible ubiquity of contemporary media and not to the physical environment as such) to do vital relational work. Starting with the digital's 'beginnings,' this article focuses on digital mineral mining to introduce what is at stake in digital metabolic thinking. It first takes a look at the 'real' stuff of media - the mineral realities of our 'elemental media' - and then it turns to the physical manual (digital) mining labor that makes our devices and networks possible.

\section{Elemental Media: Digital Minerals and Metals}

In The Marvelous Clouds, John Durham Peters argues that media are elemental in the sense that they have become of elementary importance - they have become as necessary as earth, water, fire, and air, those four considered by the ancients to be life-sustaining. We are in a time, he says, "when it is impossible to say whether the nitrogen cycle or the Internet is more crucial to the planet's maintenance" $(2015,2)$.

Unpacking Peters's terminology more thoroughly, and with an eye toward mineral materiality, we come to see that digital media are indeed elemental in another sense as well. Contrary to the manufactured narratives of the digital universe as an ether-net made of only bits, bytes, and sleek modern devices, the digital quite literally begins with(in) the earth: more metals, minerals, and chemicals pass through our digital devices than through many basic high school science labs.

Today, there are more than 60 elements and somewhere around 200 chemical compounds contained in a single pocket-sized smartphone alone, and the National Resource Defense Council (NRDC) reports that between 500-1000 chemicals are used in computer circuitry production (Rathi, 2013). Tantalum (coltan) is in your capacitor, silicon is found in your semiconductor chip and integrated circuits, copper is fused to your circuit board, lithium helps power your battery, gold lines semiconductor wire connectors, mercury and lead might be in your LCD screen, platinum coats the hard drive, and silver and tin create the glue that holds it all together. Our devices and infrastructure also contain more than a dozen different types of petrochemical plastics. Despite marketing schemes selling our digital devices as magical (see for instance the original iPad advertisement in Figure 2), oil, wires, and heavy metals are the true stuff of our magically weightless, wireless web. 


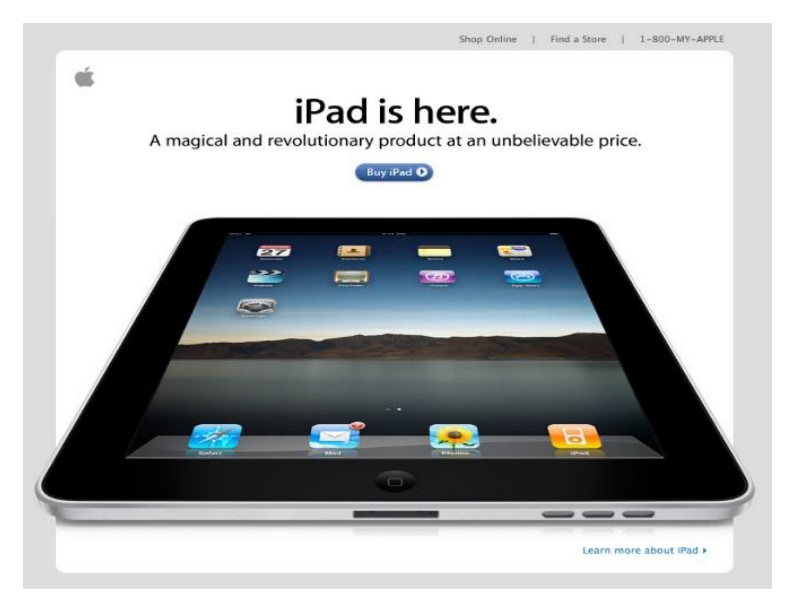

Figure 2: The "magical and revolutionary" iPad, screenshot of the original iPad advertisement sent via email to Apple customers, April 3, 2010.

These unattended materialities are the matters of fact that concern us here; to treatments of data mining and its cosmos of concerns, like data surveillance, data ownership, datafied identities, and digital cognitive labor, DEMS adds mineral mining, digital manual labor, digital carbon footprints and ecological destruction. Though according to a recent statement by IBM, big data is "the next natural resource," our digital system is dependent first on physical, elemental natural resources (Richards, 2013). Big data as a sociocultural issue or natural resource relies first on real earth-moving mining.

\section{Digital Ecological Rucksack}

Despite the motif that conceives the digital as a resource-light, eco-friendly medium, its environmental footprint, from water and energy use to ecological destruction and carbon emissions, is undeniably significant.

'Ecological rucksack' ${ }^{1}$ is a term that refers to the amount of earth which must be moved to find the minerals that become component parts and fuel for our digital infrastructure. An example calculation of a digital rucksack can be seen here from the Great Recovery Project group in the UK: "For all the mobile phones in the world today [2014], the metal in them would have required 450 million tonnes of rock to be dug up, smashed and processed. This is equivalent to $12 \mathrm{x}$ the weight of all the cars on UK roads..." (RSA, 2015, 9). The digital's ecological

\footnotetext{
1 "The concept of the "ecological rucksack" measures how many kilos of material must be mined (or grown) to produce one kilo of end-product. According to a report by NOAH, the Danish Friends of the Earth, every $1 \mathrm{~kg}$ of gold in your hand carries an invisible history of $540,000 \mathrm{~kg}$ of material in its ecological rucksack. A few other notable metals in the report: polyethylene's rucksack is a mere $2.4 \mathrm{~kg}$ of "abiotic" material per $\mathrm{kg}$ of end material, copper's is $356 \mathrm{~kg} / \mathrm{kg}$, stainless steel's is $23 \mathrm{~kg} / \mathrm{kg}$, and virgin aluminum's is $66 \mathrm{~kg} / \mathrm{kg}$, while recycled aluminum is just $1.2 \mathrm{~kg} / \mathrm{kg}$." http://www.worldchanging.com/archives/007708.html.
} 
rucksack, when expanded to include water and energy use, as well as air pollution and toxic waste, provides a helpful context for thinking about the full impact of the technosphere on the earth. The ecological rucksack of digital mineral mining alone includes substantial levels of soil erosion, air pollution, groundwater contamination, bioecological upset, toxic waste, and consumption of a remarkable amount of water and energy.

Overall, the NRDC reports that mining accounts for about 10 percent of global energy use and The Global Water Intelligence group reports that the global mining industry is the second largest industrial user of water (Casson, 2011). Parts of the mining industry have recorded a 70 percent increase in energy required for mining over the last 30 years, and that number is growing by about 6 percent per year ("Why be energy efficient?", 2015). Regrettably, the majority of the mining industry's energy is not clean (it comes from coal and fossil fuels), while the majority of the water is (it is the same freshwater that countries, states, and towns across the world are finding increasingly depleted). ${ }^{2}$ As global freshwater reserves drop to drought conditions, it becomes ever more readily evident that the digital's metabolic needs are contingent on human and ecological metabolisms. As the US Drought Monitor reports, California and several other Western states are presently experiencing "extreme" or "exceptional" drought conditions. ${ }^{3}$ In the summer of 2015, USA Today reported that "California's historic drought appears to be matched by severe dry spells on three other continents... wreaking havoc on millions of peoples' lives and livelihoods" (Rice, 2015). When The Guardian recently published an article with the headline "The tech industry is threatening to drink California dry," it wasn't so far from the truth (Shemkus, 2015). ${ }^{4}$

\section{Atmospheric Media}

In his recent Feed Forward, Hansen writes that twenty-first century media is atmospheric, or 'environmental,' in so far as it is everywhere - and with an estimated 25 billion networked things set to be connected by 2020 , this is hard to dispute - and it occurs in an always-on condition

\footnotetext{
${ }^{2}$ Recently there are trends pointing to a growing greening of the sector's energy use and though these changes are seemingly due more to cost benefits than environmental ones, the cleaning of the sector will certainly be a welcome change in our digital-environmental metabolism.

${ }^{3}$ See an interactive drought map here http://www.cnn.com/interactive/2015/05/us/map-drought/.

${ }^{4}$ What is more, it is reported that production uses between 50 and 80 percent of an electronic product's total energy requirement, and yet most of our sustainability language focuses only on the energy used to power a laptop or cellular battery (clearly a narrow focus since it only costs about $\$ 0.41$ per year to power a cellphone). A 2012 NRDC study explains that embedded energy rates for digital electronic devices are much higher than for other energy-expensive appliances like refrigerators and washing machines largely due to shorter lifetimes: digital lifetimes are 1-5 years whereas appliances and automobiles can live for decades. According to Carol Baroudi, it takes about the same amount of energy to produce a few microchips as it does to produce an entire car. To put this into context, due to the rapid accumulation of 'green' and 'smart' technologies, according to Gartner, by 2020 we should have 25 billion digitally networked things — each with its own 'ecological rucksack' — contributing to the technosphere's environmental toil.
} 
outside of our awareness. Hansen describes it this way: "the technical mediation of sensation in ubicomp [ubiquitous computing] environments is atmospheric, impersonal, collectively accessible, and microtemporal in its sensory address" (2012, 73). Environment and atmosphere, in this context, refer not to environment-as-nature or atmosphere-as-gaseous-earth-layer per se, but to the domain of experience and "environmental sensory processes" that new media enact in automated machine-to-machine interaction. When we think, however, in terms of the digital's rucksack and the environmental nature of the digital's pollutants, the rhetorical construct of ubiquitous digital technologies as 'atmospheric' rings true on a level far more literal than Hansen's intent.

According to the National Wildlife Federation,

"The hard rock mining industry is the single largest source of toxic waste and one of the most destructive industries in the country.... The mines that produce our gold, silver, copper, and uranium are notorious for polluting adjacent streams, lakes, and groundwater with toxic by-products. The Environmental Protection Agency estimates that 40 percent of the watersheds in the western United States are contaminated by pollution from hard rock mines" ("Hard Rock").

Toxic remediation of these pollution disasters is a hazardous, costly, and sometimes simply impossible task. When it comes to digital environmental media thinking, remediation resumes the meaning it had prior to Richard Grusin and Jay David Bolter's new media intervention: though they were certainly correct that re-mediation is a defining feature of the digital age, they skipped the fact that while digital media may re-mediate previous technologies, the bigger concern is that processes of digital media making may require serious environmental remediation in the truest sense of the term.

\section{The Cyborg}

Continuing our re-defining activity, we turn to the figure of the cyborg. This is another term we can easily reconfigure to facilitate more ecological thinking. A common concern of digital media theory is the physical and/or affective notion of our future-present lives as technonatural cyborgs. In this brand of thinking, popularized by films such as The Matrix, Blade Runner, Mad Max, and Avatar, the future human is one with a mind and/or body augmented by a wide range of visible and implanted digital technologies. This motif of the cyborg is no doubt inspired by the largely accepted notion that due to the proliferation of digital technologies, tomorrow's human will be a redesigned post-human techno-biological product of digital enhancement.

We can see this too appearing in digital theory where the human body is now imagined as coded or cellularized, and is seen to be "integrated with digital circuits...the digital nervous system 
incorporates itself progressively in the organic nervous system, in the circuit of human communication, and re-codifies it..." (Berardi, 2012, 142-143). When thinking metabolically about the physical body's relationship to the digital network and the earth, this human-digital integration figures differently: in DEMS thinking, our nervous systems are becoming digital though biophysical and ecological interaction with the material stuff of the digital network.

There is a flashy diagram circulating the web, largely popularized by Ray Kurzweil's TEDxSiliconAlley talk on the Singularity, ostentatiously titled "How To Create A Mind," that shows a Darwinesque evolution of human bodies that moves from ape to homo sapiens to a burst of computational data in a cloud. ${ }^{5}$ A similar, and probably not unfamiliar, diagram can be found here, in Figure 3, where the human evolves from ape to human to robot:

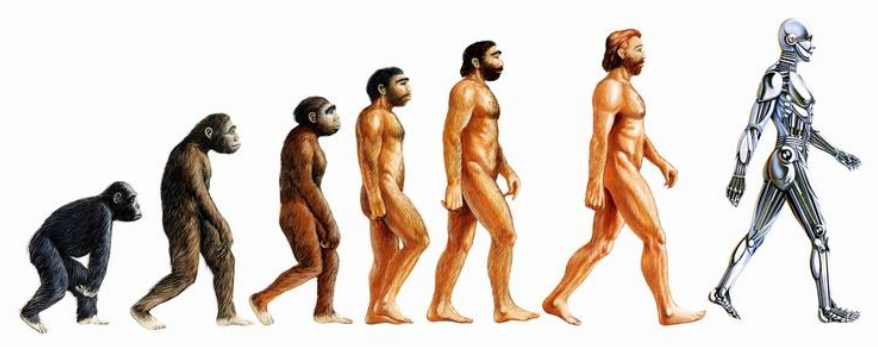

Figure 3: Modern Evolution, source: http://ichef.bbci.co.uk/images/ic/1200x675/p0338yd1.jpg

In Kurzweil's version, the human is more or less subsumed into a computer screen and then shot into an orbiting satellite (which is a curious error since wireless infrastructure and data centers are located on and under the earth and oceans). The argument is that the future body is a cyborg configuration that isn't really a body at all but a container for a downloaded brain. ${ }^{6}$

What is missing from this provocative techno-evolutionary stance is the recognition that long before our bodies turn into pure computation, they'll be biologically and biophysically altered by the bioaccumulation of technology-related toxins and environmental habitat destruction. This more imminent evolution is what we should be streaming; the cyborg concept prepares us for thinking about human-machine coupling, we just need to think about it differently.

One way forward toward illustrating a re-narrated digital body is to re-story the bodies that do our digital mining labor.

\footnotetext{
${ }^{5}$ See animation: Ray Kurzweil at TEDxSiliconAlley, Video link here begins the clip where we want to begin - from about minute 17:38 to about minute 18. http://youtu.be/RIkxVci-R4k?t=17m38s.

${ }^{6}$ Kurzweil has diagrams that he says supports this prediction.
} 


\section{Re-narrating Digital Labor}

Though digital media and cultural scholars have written rather extensively on the 'cognitive' and 'immaterial' labors associated with the digital universe (see for instance the Digital Labor collection edited by Trebor Scholz and the work done by Jonathan Beller, Tiziana Terranova, and Maurizio Lazzarato, to name a few), the critical mapping of the particular physical labors associated with our digital age is far less prolific. As Christian Fuchs outlines:

"In its first phase, the digital labor debate has focused on understanding the valuecreation mechanisms of corporate social media such as Facebook, YouTube, and Twitter...The general task has been how to best understand and conceptualize that users under real-time, far-reaching conditions of commercial surveillance create a data commodity that is sold to advertising clients and that users essentially create value that manifests itself in social media corporations' profits" $(2015,53)$

The stories not often told, and sometimes deliberately hidden, are of the manual digital labor done in digital mineral mines. These laborers - most often men but certainly too women and sometimes even children - are, in certain locations and circumstances, subjected to deplorable, toxic working conditions. Transferring our humanistic gaze from digital users to digital manual laborers reveals the marginalized bodies that are hidden by our fetishistic fascination with the digital's magical, Cloud-based immateriality. These bodies are subjected daily to the ills of the digital's ecological rucksack.

In Geology of Media, Parikka approaches digital labor through dust. During production and manufacturing stages, great measures are taken to ensure there is no dust in our digital machines as dust could render them unworkable. At the same time, though, as Parikka points out, dust from the processes involved in mining the minerals required for those computers to work is actually harming the workers who inhale it.

Dust shows us one example of how digital materiality mingles with the body and the environment in ways uncaptured by current media theory frameworks. Dust gives us a new way of thinking about how the digital truly in-corporates into the human nervous system. Dust not only reveals the human bodies and labor practices associated with digital capitalism, but also shows that the materiality of the clean, sleek iDevice is actually a very dirty materiality-one made possible only by the physical labor of sometimes dangerously dirty work: "The materiality of minerals and metals, from silicon to coltan, is entangled with the materiality of the lungs. In other words, this is the materiality of hardwork [sic] that connects to the labor sustaining the hardware" (Parikka, 2015b, 92). Mineral mining is, as Parikka says, "media work in and through bodies," (ibid, 93) and without proper protections, the laborers are working in seriously noxious conditions, all in the service of producing the materials and the devices used to make our so- 
called 'green' technologies possible (and invisible). ${ }^{7}$ These are the types of stories we must tell alongside our 'cognitive' digital labor narratives.

It isn't just miners and manufacturing laborers who are affected but also the general public. Tissue samples have shown that breast-feeding human mothers are tainted with the synthetic chemicals used to make our technologies fire resistant. In High Tech Trash, Elizabeth Grossman reports that these chemicals are most prevalent in Americans and that these chemicals have actually been found in foods on our grocery store shelves (2006, 1-2). Mining chemicals such as mercury, arsenic, lead, cadmium, and sulfuric acid have been found in run-off and groundwater reserves used by communities in locations near mines. These are dangerous neighbors: arsenic has shown to be cancerous and deadly, as has sulfuric acid; overexposure to cadmium can cause kidney disease, lung disease, and weakening of the bones; mercury and lead are equal opportunity offenders as they can affect any bodily organ and can damage reproductive systems (Martin and Griswold, 2009, 1-4). These metals can also accumulate in the bodies of animals and aquatic wildlife, and in the roots and shoots of plants (ibid, 5). We are all eco-digital cyborgs now.

The digital's ecological rucksack illustrates how mineral mining, human bodies, and environmental destruction are metabolically concomitant. Minerals make digital media an ecological matter of concern, and the environment a digital issue that must be carefully considered. If we premise media work as work performed only by interface designers, software engineers, and tech-savvy Internet users, we can easily overlook the physical (hi)stories that accompany our digital lifestyles. The Internet, our digital devices, and the global social network, however, are made first by real bodies doing real physical work. What digital environmental media thinking makes clear is that manual labor is an inescapable companion to all $21^{\text {st }}$ century cognitive labor.

\section{'Real' Digital Social Networks}

What follows very closely from the radically detrimental human health conditions of some of our digital mines are the sometimes equally violent social and political situations that drive the digital mining and manufacturing industries.

\footnotetext{
${ }^{7}$ Miners and factory laborers are exposed to chemical environments that include mercury, lead, radioactive radiation, cadmium, barium, and hexavalent chromium. The mining industry relies on chemicals as aides to mineral and metal extraction. These can cause, among other symptoms, damage to the heart, liver, spleen, kidneys, and central and peripheral nervous systems. They can cause brain swelling and muscle weakness as well as birth defects and death. Silver and silicon dust can result in breathing problems in laborers as well as lung, throat, and stomach irritation. Gold mining, for example, uses, among other noxious chemicals, cyanide and mercury. In fact, in the United States, gold mining is a major producer of mercury pollution (Grossman, 2006; Martin and Griswold, 2009; Parikka, 2015b) .
} 
Greenpeace, the International Labour Organization, the United Nations, the Basel Action Network, and other NGOs have recently launched reports detailing a harsh material reality for those doing the manual labor of the digital network. Where this is beginning to register in the humanities and in media theory is through work by, for instance, Grossman, Cubitt, Parikka, Sy Taffel, and the collected authors in the important Challenging the Chip project. In their research, stories of slave labor, war, drug trades, toxic chemical and metal exposure, and cruel capitalism are threaded through digital media as constitutive digital social realities. If we are to talk about how the digital alters the social, we cannot ignore how these social structures lie alongside those more affective issues, like attention, distraction, social etiquette, data privacy, online ethics, computation/algorithmics, and social media labor, for instance, to which media scholars tend to give primacy.

Certainly not all mines are improperly or violently deployed, but minerals and metals from conflict mines are finding their way into our digital technologies. And, according to ibtimes.com American companies are looking askance:

"Nearly 80 percent of American companies are failing to adequately check their supply chain for "conflict minerals," which are sourced from war-torn regions in Central Africa, according to a new report by Amnesty International and Global Witness. A survey of 100 U.S. firms published in the report, titled "Digging for Transparency," reveals that only 21 percent of companies are adhering to U.S. laws prohibiting the use of conflict minerals" (Pandey, 2015).

The major technology companies are now trying to distance themselves from these conflict elements, but it is proving difficult. Minerals from the Democratic Republic of the Congo (DRC), for instance, are prohibited for use by US companies but are almost impossible to trace. It has been reported that countries near the DRC, like Rwanda and Burundi, are selling minerals that they have no local stores of themselves, and the DRC is intentionally using such intermediaries - as many as ten or more - to move its 'conflict' minerals (Taffel, 2012, 9). In so doing, it is injecting these minerals into the conflict-free stream. What is more, many of these minerals are shipped to smelters in places such as China and Kazakhstan where there is little tracking and oversight. Illegal coltan mining and manual labor practices have not only destroyed bodies but also full ecological systems. In the DRC,

"Illegal mining camps in national parks have also lead to miners hunting endangered species such as Grauer's Mountain Gorilla (Taylor \& Goldsmith, 2002: 421) and elephants (UN 2001) as food. Miners hunt these animals due to a lack of alternative food sources; given the choice between bushmeat from endangered species and starvation it is hard to blame the miners for feeding themselves. Problems of starvation are linked to land use change surrounding agricultural land converted into artisanal coltan mines..." (Taffel, 2012, 13). 
In 2014 and again recently in 2015, Intel said it would go 'conflict free' by 2016 but with inadequate auditing methods and deliberate obstruction by the DRC, many in the activistacademic community are openly dubious (see researcher Denisa Kera for instance). Apple joined the Conflict-Free Sourcing Initiative in 2009, but still in late 2015 its annual report said that it was not yet conflict free: "Of the 233 smelters and refiners that furnished these minerals used in Apple products last year, 24 were from the Democratic Republic of Congo or adjoining countries" (Chmielewski' 2015).

In 2012, the Enough Campaign ranked digital electronics companies - many of them signatories to the Conflict-Free Sourcing Initiative-based on their efforts toward reducing conflict minerals. Toward the top were Intel and HP; toward the bottom were Samsung, Sharp, and Nintendo. ${ }^{8}$ Even the newest of phones and digital devices today might contain coltan, gold, tantalum, or tin from the war-torn areas of the DRC. Older devices are even more likely to contain them. Our 'immaterial' digital devices have deep and complex material histories that must be narrated if we are to have more meaningful understandings of the digital's materiality. It is worth quoting Ted Smith and Chad Raphael at length:

"One of the sharpest ironies of the Information Age is that it is easier for electronics to trace people than for people to trace the materials and labor that make their electronics. A fragmented global supply chain conceals who makes what, how they make it, and with what materials. Electronics companies have a strong incentive to conceal this supply chain from their employees, customers, and even from top management: it is filled with hazards for workers and their communities that tarnish the image of a clean industry of the future. Even the major brand owners - Apple, Dell, and the like - do not know all of the materials and chemicals that end up in these companies' own products" $(2015,78)$

The game Phone Story, released in 2011 by Molleindustria, was created in part to publicize these digital mineral mining abuses. ${ }^{9}$ Designed as a basic four-level game for Apple's iPhoneoriginally loaded to, but then very quickly banned from, the Apple App Store-Phone Story takes the game player (the phone user) through coltan mines, Foxconn factories, e-waste heaps in Pakistan, and corporate Western offices where the planned obsolescence of these devices is deliberately designed. According to the game developers, "Phone Story is a game for smartphone devices that attempts to provoke a critical reflection on its own technological platform" (Phone Story, 2011). The mining level shows a line of young-looking barely-clothed crouching miners (children?) being guarded by gun-carrying men in military gear. The player's objective is to help

\footnotetext{
${ }^{8}$ See the full ranking and report: http://www.raisehopeforcongo.org/content/conflict-minerals-company-rankings-0.

${ }^{9}$ Game Credits: A game by Molleindustria; Original concept and website content: Michael Pineschi; Voice: Jesse Stiles; Music: "Derecha" by Minusbaby - 8BP110; Thanks: Soyo Lee, Olivia, Tenley, YesLab; Supported by: AND festival, Gwangju Design Biennale. The game can be downloaded onto Android devices and played online. A full video walkthrough can be found: https://www.youtube.com/watch?v=sSMSFLAsNzc
} 
the miners mine quickly enough, by forcing them to work, in order to 'save' the miners from being killed by the gunmen. In the background, a voice tones "Once upon a time, there were minerals resting in the bowels of the earth. One of these minerals, called coltan, is found in most electronic devices. The majority of coltan's world supply is located in Congo, a country torn by a brutal civil war. The increasing demand of coltan produced a wave of violence and massacres in Congo. Military groups enslaved prisoners of war, often children, to mine the precious material" (ibid, 2011).

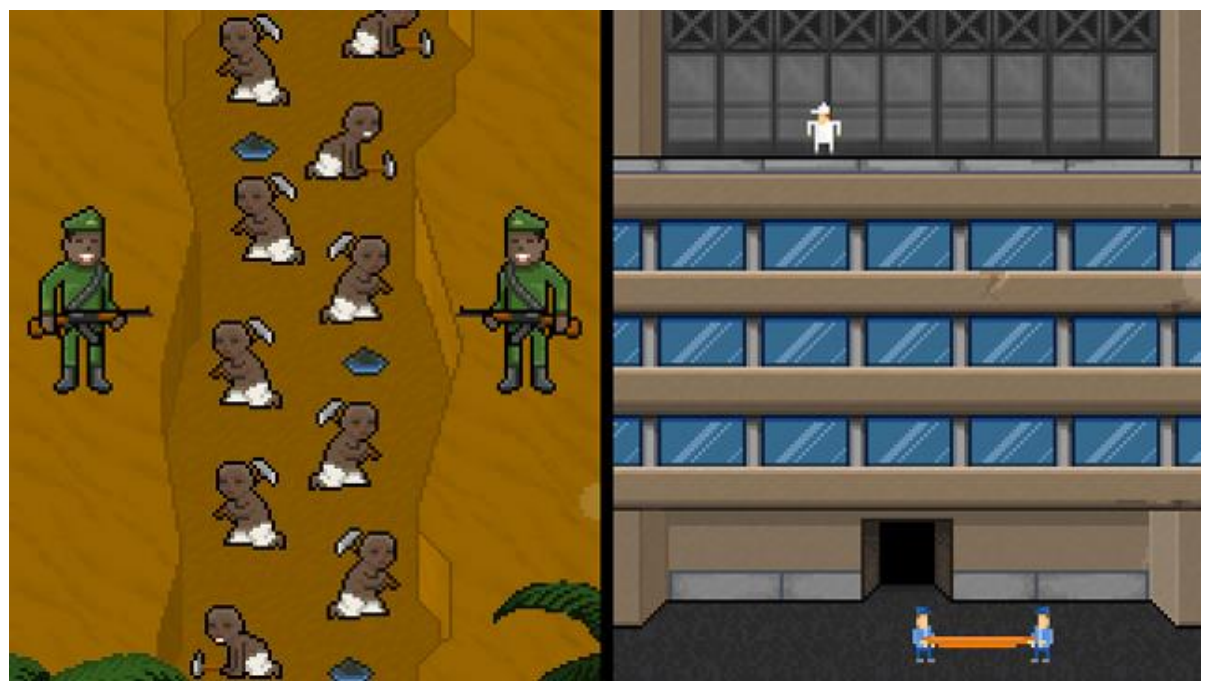

Figure 3, Screenshot from Phone Story, source: http://kotaku.com/5883744/phone-story-proceedswill-be-given-to-foxconn-employee-who-attempted-suicide

The game hopes to remind users that "When you buy a gadget, you aren't only buying the sleek image the companies [sic] advertising team worked so hard to create, you are also buying the whole line of production used to create it" (ibid, 2011). By being released first only on the iPhone operating system, the game deliberately implicated its users in the dirty production practices that come as a result of their own digital consumption. This is the type of intervention that can re-narrate the digital story and elucidate the porous connections in the human-computerearth relationship. Digital labor has never been strictly immaterial.

\section{Conclusion}

What mapping digital mineralities makes evident is that when we equate digital mining with data mining, and digital production with programming, we are overlooking important material facts, and as follows, important matters of concern. ${ }^{10}$ Our ignorance of the 'real' digital miners and

\footnotetext{
${ }^{10}$ See Bruno Latour's "Why Has Critique Run Out of Steam? From Matters of Fact to Matters of Concern" on matters of fact and/as matters of concern.
} 
makers perpetuates the myth of immateriality, thus excusing us from the responsibilities of our consumption. It is said that these technologies, with their endless communicative connective capabilities, link places far and wide together into a transgeographic 'global village,' but the material truth of the digital reveals that our digital technologies connect us even more literally to places and people across the world by way of the minerals, metals, pollutants, waste, and labors that compose them.

Our phones, as well as our laptops, tablets, and smart-enabled devices, are part of a vast humanand natural resource-intensive system (digital metabolism). Each device begins in the mines, proceeds to a manufacturing plant, and returns to the earth as waste after its deliberately short lifetime. Cumulatively across the globe in 2014, 1.2 billion new cell phones were purchased and this was up 28.4 percent from 2013 (“Gartner Says," 2015). Keep in mind that many of us have half a dozen or more (sometimes far more) other digital devices in our homes. Globally 4.5 billion people used cell phones and more than 300 million bought new PCs in 2014. In the US alone, there are more than 400 million rechargeable electronic devices (U.S. DOE 2013)" (Behdad et al., 2010). If we continue at this rate, we'll be activating new phones at a phenomenal pace. Yet we prefer new phones to considerations of the contingency and consequentiality they embody. "We must not forget" Maxwell and Miller write in Media and the Ecological Crisis, "that our high-tech subject matter comes into being at tremendous cost to the Earth's ecosystems and the biophysical health of its organisms...delinking our high-tech systems from their real ecosystem contexts in this way reinforces a dangerous ecological-amnesia" (2015, 90-93). DEMS attempts to re-story the digital narrative by highlighting the absences, the ungrounded abstractions, and the metabolic consequences of our digital actions.

When we create robust relational narratives that more adequately reflect the full force of the digital's geophysical contingencies, we make positive steps toward a more sustainable digital media studies. This essay has suggested that generating new narratives by re-defining our terms is one way forward. In shifting the way we think and relate to the technosphere and the geosphere, digital environmental media studies is an example of how we might intervene in contemporary crises (like climate change, for instance), not by throwing out our terms, but by disengaging their abstract meaning to invoke more concrete and environmentally-aware patterns, practices, and processes of thinking for contemporary digital media studies. Though I commend the president for his Instagram glacier selfie, I believe this is how we might more sustainably \#ActOnClimate. 


\section{References}

Baroudi, C. (2015) "Electronics and Embedded Energy Blog," March 16, 2015, http://blog.arrowvaluerecovery.com/electronics-and-embedded-energy/\# ftn1.

Behdad, S. et al. (2010) "PCRR E-waste Stream Analysis" SEI Reports, Illinois Sustainable Technology Center, SEI TR-001.

Berardi, F. (2012) "Soul Work," in C. Wiedemann and S. Zehle (eds) Depletion Design: A Glossary of Network Ecologies, Amsterdam: Institute of Network Cultures.

Bolter, J. and Grusin, R. (2000) Remediation: Understanding New Media, Cambridge: MIT Press.

Casson, C. (2011) "Don't Waste a Drop - Water in Mining," Mining Magazine October 2011, http://www.globalwaterintel.com/dont-waste-drop-water-mining/.

Chmielewski, D. (2015) "Apple Reports Progress in Eliminating 'Conflict Minerals' From Its Devices," Recode.net, February 12, 2015, http://recode.net/2015/02/12/applereports-progress-in-eliminating-conflict-minerals-from-its-devices/.

Coole, D. and Frost S. eds (2010) New Materialisms: Ontology, Agency, and Politics. Durham: Duke University Press.

"Fifty Years of Moore's Law Made Possible by Semiconductor Equipment and Materials Suppliers Worldwide," (2015) April 14, 2015, http://www.semi.org/node/55676.

"Five things you need to know about coltan," (2012) International Consortium of Investigative Journalists, March 4, 2012, http://www.icii.org/projects/coltan/fivethings-you-need-know-about-coltan.

Fuchs, C. (2015) "Dallas Smythe and Digital Labor" in R. Maxwell (ed) Routledge Companion to Labor and Media, New York: Routledge.

"Gartner Says Smartphone Sales Surpassed One Billion Units in 2014," (2015) Egham, UK, March 3, 2015, http://www.gartner.com/newsroom/id/2996817.

Gonzalez, A. et al. (2012) "What We Know and Don't Know about Embodied Energy and Greenhouse Gases for Electronics, Appliances, and Light Bulbs," Natural Resources Defense Council, 2012 ACEEE Summer Study on Energy Efficiency in Buildings. 
Grossman, E. (2006) High Tech Trash: Digital Devices, Hidden Toxics, and Human Health, Washington, DC: Island Press.

Haff, PK. (2014) "Technology as a geological phenomenon: implications for human wellbeing, Geological Society special publication, vol 395 no. 1, 301-309.

Hansen, M. (2015) Feed Forward: On the Future of 21st Century Media, Chicago: University of Chicago Press.

Hansen, M. (2012) Ubiquitous Sensation or the Autonomy of the Peripheral: Towards an Atmospheric, Impersonal and Microtemporal Media, in U. Ekman (ed) in Throughout: Art and Culture Emerging With Ubiquitous Computing, Cambridge: MIT Press.

Hansen, M. and Mitchell, WJT. (2010) Critical Terms for Media Studies, Chicago: University of Chicago Press.

Hansen, M. (2006) Bodies in Code: Interfaces with New Media, New York: Routledge.

Haraway, D. (2015). "Anthropocene, Capitalocene, Plantationocene, Chthulucene: Making Kin," Environmental Humanities, vol. 6, pp. 159-165.

"Hard Rock Mining Pollution," (n.d) National Wildlife Federation, http://www.nwf.org/What-We-Do/Energy-and-Climate/Drilling-and-Mining/MiningLoopholes.aspx.

Hayles, K. (2009) "RFID: Human Agency and Meaning in Information-Intensive Environments," Theory, Culture and Society: Explorations in Critical Social Science, vol. 26 no. $2 / 3$.

Hayles, K. (2012) How We Think: Digital Media and Contemporary Technogenesis, Chicago: University of Chicago Press.

Klare, M. (2012) The Race for What's Left: The Global Scramble for the World's Last Resources, New York: Metropolitan Books.

Kroker, A. and Weinstein, M. (1994) Data Trash: The Theory of Virtual Class, New York: St. Martin's Griffin.

Latour, B. (2004) "Why Has Critique Run Out of Steam? From Matters of Fact to Matters of Concern," Critical Inquiry, vol 30 no 2, pp. 225-248.

Latour, B. (2013) An Inquiry Into Modes of Existence, Cambridge: Harvard University Press. 
Latour, B. (2015) "Fifty Shades of Green," Environmental Humanities, vol. 7, pp. 219225.

Martin S. and Griswold, W. (2009) "Human Health Effects of Heavy Metals," Center for Hazardous Substance Research, Environmental Science and Technology Briefs for Citizens, Issue 15.

Maxwell, R. and Miller, T. (2012) Greening the Media, New York: Oxford University Press.

Maxwell, R. et al, eds (2015) Media and the Ecological Crisis, New York: Routledge.

Pandey, A. (2015) "Conflict Minerals Enter US Unchecked, Hidden By 'Blind Spots' In Supply Chains," April 22, 2015, http://www.ibtimes.com/conflict-minerals-enter-usunchecked-hidden-blind-spots-supply-chains-1891692.

Parikka, J. (2015a) Anthrobscene, Minneapolis: University Of Minnesota Press.

Parikka, J. (2015b) A Geology of Media, Minneapolis: University Of Minnesota Press.

Peters, J.D. (2015) The Marvelous Clouds: Toward a Philosophy of Elemental Media. Chicago: University of Chicago Press.

Phone Story (2011) Molleindustria. Video game, phonestory.org.

Pötzsch, H. and Hayles, K. (2014) "FCJ-172 Posthumanism, Technogenesis, and Digital Technologies: A Conversation with N. Katherine Hayles" The Fibreculture Journal, Issue 23

Prosser, I. et al. (2011) "Water in mining and industry," in Water: Science and Solutions for Australia, Australia: CSIRO Publishing.

"Pure water, semiconductors and the recession." (2009) Global Water Intelligence (GWI). 10.10 .

Rathi, A. (2013) "The metals in your smartphone may be irreplaceable," December 5, 2013, http://arstechnica.com/science/2013/12/the-metals-in-your-smartphone-maybe-irreplaceable/.

Richards, H. (2013) "IBM's "Ginni” Rometty Predicts Three Ways Technology Will Transform The Future Of Business," September 3, 2013, Intelligenthq.com, http://www.intelligenthq.com/intelligence/ibms-ginni-rometty-predicts-three-waystechnology-will-transform-the-future-of-business/. 
Rice, D. (2015) "On four continents, historic droughts wreak havoc," USA Today, July 27, 2015, http://www.usatoday.com/story/news/world/2015/07/24/historic-droughtswreak-havoc-usa-brazil-n-korea/30513289/.

The Royal Society for the Encouragement of Arts, Manufactures and Commerce (RSA), (2014), "Great Recovery Report," September 2014, http://www.greatrecovery.org.uk/resources/the-great-recovery-report/.

Scholtz, T. (2012) Digital Labor: The Internet as Playground and Factory, New York: Routledge.

Shemkus, S. (2015) "The tech industry is threatening to drink California dry," July 20, 2015, http://www.theguardian.com/sustainable-business/2015/jul/20/water-californiadrought-tech-gaints-data-centres.

Smith, T and Raphael, C. (2015) "Health and Safety Policies for Electronics Workers" in In Maxwell, R (ed) The Routledge Companion to Labor and Media, New York: Routledge.

Taffel, S. (2012) "Escaping Attention: Digital Media Hardware, Materiality and Ecological Cost" Culture Machine vol. 13.

"Water Use in the Semiconductor Manufacturing Industry," (2013) August 8, 2013, http://engineeredenvironment.tumblr.com/post/30464844411/water-use-in-thesemiconductor-manufacturing.

Williams, R. (1980) Problems in Materialism and Culture, Brooklyn: Verso Press.

"Why be energy efficient?" (2015) Australian Government Department of Industry, Innovation and Science, http://eex.gov.au/industry-sectors/mining/.

"Your Computer's Lifetime Journey," (2011) Natural Resources Defense Council, ArsTechnica, November 30, 2011, http://www.nrdc.org/living/stuff/your-computerslifetime-journey.asp.

Amanda Starling Gould, a PhD candidate in Duke University's Program in Literature, is a James B. Duke Scholar, a member of the Franklin Humanities Institute Digital Humanities Initiative Advisory Board, and an Andrew W. Mellon Foundation Humanities Writ Large 
Environmental Humanities Emerging Networks Fellow. She is currently finishing her dissertation, Digital Metabolisms: Mapping a Digital Environmental Humanities through Materiality, which traces the complex intersections of digital media and the environment, and questions the absence of environmental thinking from digital theory. The project re-stories media theory representations of the 'immaterial' digital, and presents Eco-Critical DH and permaculture as methods for sustainable digital practice. More about her publications, teaching, and digital projects can be found on amandastarlinggould.com, on HASTAC, and at @ stargould. Her work can be found in bot form at @ stargouldbot.

Email: amandastarling@gmail.com 